\title{
Decline in rate of death from ischaemic heart disease in the United Kingdom
}

\author{
R F HELLER, D HAYWARD, M S T HOBBS
}

\begin{abstract}
The rates of death from ischaemic heart disease in the United Kingdom in the years after 1968 were studied to establish whether any general trend had occurred. A decline in the rates began after 1973-4, was greatest in those aged 35-44 years, and occurred among both men and women and in each of the regions of England and in Wales and Scotland. Total dietary fat intake had started to fall about five years earlier, and this may provide part of the explanation. Changes in smoking habits also occurred but were more difficult to relate to the pattern of change in the death rates.

If a general decline in ischaemic heart disease has begun in the United Kingdom a case may be made for close monitoring of changes in lifestyle and medical practice in different demographic groups to try to find the explanation.
\end{abstract}

\section{Introduction}

In the USA and Australia death rates from ischaemic heart disease declined by roughly one-quarter over the past decade. ${ }^{1}$ No similar decline occurred in the United Kingdom, and in the early 1970 s the rates were still increasing, whereas they were already falling rapidly in the USA and Australia. A detailed examination of the patterns up to $1976^{2}$ suggested that in the UK the increase had stopped and that a decline might be beginning; this was confirmed by the 1980 mortality figures for England and Wales. ${ }^{3}$

This paper documents this trend. The change in the rate of death from ischaemic heart disease by region and the changes in fat intake and smoking habits that had occurred over the past few years were explored in an attempt to explain the decline.

\section{Methods}

Death rates from ischaemic heart disease (International Classification of Diseases 410-414) were obtained from published tables for England and Wales ${ }^{3} 4$ and for Scotland. ${ }^{5}$ Within England and Wales rates were examined separately for five parts of the country obtained in some cases by amalgamating the data from standard regionsnamely, the north (incorporating the north, Yorkshire and Humberside, and the north west); the Midlands (east and west Midlands); the south east (London and the south east and East Anglia); the south west; and Wales.

Death rates during the years from 1968 (when there was a major change from the seventh to the eighth revision of the International Classification of Diseases) to 1979 or 1980 were examined using threeyear moving averages for men and women for the ages 35-44, 45-54, and 55-64. This suggested that in most age and sex groups a peak in

Department of Community Medicine, St Thomas's Hospital Medical School, London SE1 7EH

R F HELLER, MD, MRCP, reader

D HYWARD, BSC, SRD, research assistant

Department of Medicine, University of Western Australia M S T HOBBS, DPHIL, FRACP, associate professor the disease occurred around 1973-4. To show differences across the period studied mean rates were computed for each of the two-year periods $1968-9,1973-4$, and 1979-80. For regional analyses the means of the rates in 1978 and 1979 were used as the 1980 data were not available by region. Information on the mean fat intake in the same regions was obtained from the Ministry of Agriculture, Fisheries and Food, ${ }^{6}$ and on smoking habits from the Tobacco Research Council, ${ }^{7}$ the General Household Survey, ${ }^{8}{ }^{9}$ and unpublished data from Research Services Ltd (provided by the Tobacco Advisory Council).

\section{Results}

Table I shows that in England and Wales and in Scotland among men and women in each age group death rates from ischaemic heart disease increased between 1968-9 and 1973-4 (except among women aged 35-44 in England and Wales, in whom there was no change). Between 1973-4 and 1979-80 the rates fell in each age group in England and Wales and in Scotland among both men and women (except in Scottish women aged 45-54, in whom there was no change). In the youngest age group the rates in 1979-80 were lower than those in 1968-9; in the other groups the rates in 1979-80 were lower than those in 1973-4 but had not fallen to the 1968-9 levels. Examination of death rates by region showed a similar pattern in each region among both men and women (fig 1; only men shown). Despite the similarities in the pattern between the regions the north and the Midlands showed the smallest and Wales, the south east, and the south west the largest reductions in ischaemic heart disease.

Fat intake has increased over the twentieth century but started to fall after 1968-9 (fig 2). This fall occurred to a similar extent in each region, although there was some variation, with Wales, the south east, and the south west showing the largest and Scotland and the Midlands the smallest reductions in fat intake. These data were derived from the food purchasing habits of the women of the household and were not

TABLE I-Changes in death rates from ischaemic heart disease

\begin{tabular}{|c|c|c|c|c|c|c|}
\hline \multirow{3}{*}{ Age } & \multirow{2}{*}{\multicolumn{2}{|c|}{$\begin{array}{c}\text { Rate in } 1968-9 \\
(/ 100000 \text { population })\end{array}$}} & \multicolumn{4}{|c|}{$\%$ change from $1968-9$} \\
\hline & & & \multicolumn{2}{|c|}{ To 1973-4 } & \multicolumn{2}{|c|}{ To $1979-80$} \\
\hline & $\begin{array}{c}\text { England } \\
\text { and } \\
\text { Wales }\end{array}$ & Scotland & $\begin{array}{c}\text { England } \\
\text { and } \\
\text { Wales }\end{array}$ & Scotland & $\begin{array}{l}\text { England } \\
\text { and } \\
\text { Wales }\end{array}$ & Scotland \\
\hline $\begin{array}{l}35-44 \\
45-54 \\
55-64\end{array}$ & $\begin{array}{r}62 \\
250 \\
704\end{array}$ & $\begin{array}{r}82 \\
328 \\
875\end{array}$ & $\begin{array}{l}\text { Men } \\
+4 \\
+15 \\
+4\end{array}$ & $\begin{array}{r}+2 \\
+13 \\
+10\end{array}$ & $\begin{array}{r}-12 \\
+8 \\
+2\end{array}$ & $\begin{array}{r}-13 \\
+7 \\
+3\end{array}$ \\
\hline & & & Women & & & \\
\hline $\begin{array}{l}35-44 \\
45-54 \\
55-64\end{array}$ & $\begin{array}{r}11 \\
43 \\
187\end{array}$ & $\begin{array}{r}14 \\
77 \\
396\end{array}$ & $\begin{array}{r}0 \\
+20 \\
+11\end{array}$ & $\begin{array}{l}+21 \\
+14 \\
+10\end{array}$ & $\begin{array}{r}-19 \\
+16 \\
+9\end{array}$ & $\begin{array}{r}-7 \\
+14 \\
+2\end{array}$ \\
\hline
\end{tabular}

35-64 yeors

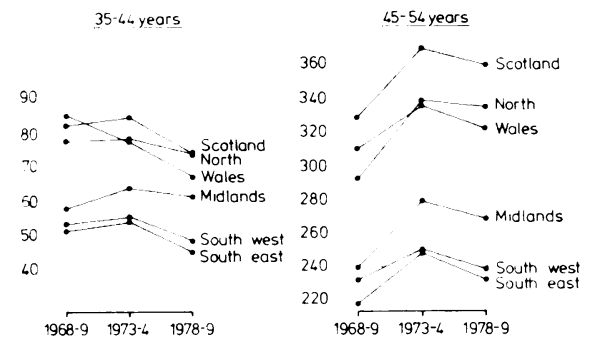

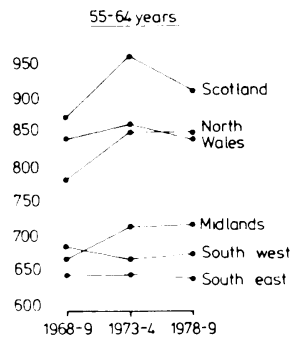

FIG 1-Deaths from ischaemic heart disease/100 000 men according to age 
available for the sexes separately. Between 1969 and 1979 (data were not available for the years in between) total fat intake fell by $11 \%$, $12^{\circ} \circ$, and $10^{\circ} \circ$ in the groups aged $35-44,45-54$, and 55-64 respectively. In addition to the changes in total fat intake the type of fat eaten changed: in particular, consumption of butter was reduced and that of soft margarines increased. The ratio of polyunsaturated to saturated fat in the diet increased from $0 \cdot 19$ in 1969 to $0 \cdot 23$ in $1979 .^{6}$

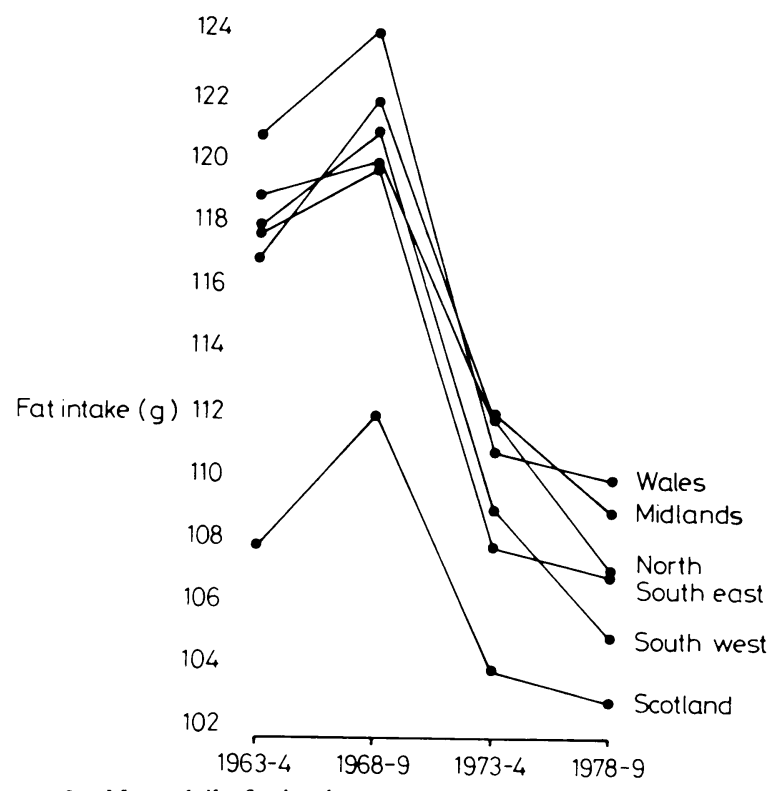

FIG 2-Mean daily fat intake.

TABLE II-Percentage of adults in UK smoking any tobacco product

\begin{tabular}{|c|c|c|c|c|c|c|c|c|}
\hline & \multicolumn{4}{|c|}{ Men } & \multicolumn{4}{|c|}{ Women } \\
\hline & \multirow{2}{*}{$\begin{array}{c}\text { All } \\
\text { ages }\end{array}$} & \multicolumn{3}{|c|}{ Age group } & \multirow{2}{*}{$\begin{array}{c}\text { All } \\
\text { ages }\end{array}$} & \multicolumn{3}{|c|}{ Age group } \\
\hline & & $35-49$ & $50-59$ & $60+$ & & $35-49$ & $50-59$ & $60+$ \\
\hline $\begin{array}{l}1959-60 \\
1963-4 \\
1968-9 \\
1973-4 \\
1979-80\end{array}$ & $\begin{array}{l}73 \\
69 \\
69 \\
65 \\
55\end{array}$ & $\begin{array}{l}75 \\
72 \\
71 \\
68 \\
58\end{array}$ & $\begin{array}{l}76 \\
72 \\
73 \\
69 \\
57\end{array}$ & $\begin{array}{l}73 \\
67 \\
67 \\
63 \\
52\end{array}$ & $\begin{array}{l}42 \\
42 \\
44 \\
44 \\
40\end{array}$ & $\begin{array}{l}53 \\
54 \\
54 \\
54 \\
44\end{array}$ & $\begin{array}{l}39 \\
42 \\
46 \\
50 \\
48\end{array}$ & $\begin{array}{l}20 \\
23 \\
24 \\
26 \\
25\end{array}$ \\
\hline
\end{tabular}

Source: Research Services Ltd.

TABLE III-Average annual consumption of all tobacco products per adult in UK $(\mathrm{kg}$ ! person/year)*

\begin{tabular}{lcc}
\hline & Men & Women \\
\hline 1961 & $4 \cdot 9$ & $1 \cdot 7$ \\
1963 & $4 \cdot 6$ & $1 \cdot 7$ \\
$1968-9$ & $4 \cdot 0$ & $1 \cdot 7$ \\
$1973-4$ & $3 \cdot 8$ & $1 \cdot 9$ \\
$1979-80$ & $3 \cdot 3$ & $2 \cdot 0$
\end{tabular}

*Figures not available for 1959,1960 , or 1964 Source: Reference 7 and Research Services Ltd.

Smoking habits also changed over time. In the early 1960s the proportion of men who smoked started to decline; there was then a relatively stable period until the middle of the $1970 \mathrm{~s}$, after which a larger decline occurred (table II). In women the proportion of smokers increased until the second half of the 1970s, when a small decline occurred (table II). We could not break the data down into the age groups used elsewhere in this study, but within the age range considered here there was little difference by age among men (a small trend towards a greater reduction in older men) while in women the youngest age group (35-49) was the only one in which the proportion of smokers really declined. The average consumption of tobacco per adult (table III) again showed a different pattern between men and women, with a steady decline among men and a continuing increase among women. Regional differences in smoking habits ${ }^{8}$ were only small, and we could not examine time trends since smoking data are no longer given by region in the General Household Survey because of worries about small sample size. The decline in cigarette smoking was greatest among those in social class $\mathrm{I}^{9}$ : when the $1980-2$ data on occupational mortality become available it will be interesting to compare the trends in heart disease across the 1970 s in different social classes.

The type of cigarette smoked changed greatly, towards those with filter tips and lower tar and nicotine contents. The change away from plain cigarettes was examined in some detail: the share of the market held by plain cigarettes fell from $66 \%$ in $1963-4$ to $11 \%$ in $1979-80$ in men and from $39 \%$ to $3 \%$ in women. The greatest part of this change occurred between 1963-4 and 1968-9, and it was more pronounced in the younger age groups in both men and women (data supplied by Research Services Ltd). The reduction in tar and nicotine yields first began to occur in about the mid 1960s. ${ }^{7}$

\section{Discussion}

The main purpose of this report was to document the observation that rates of death from ischaemic heart disease in the United Kingdom appear to be falling. The fall is unlikely to be due to changes in the classification of diseases. The ninth revision of the International Classification of Diseases was changed further in 1979, resulting in small changes in the definition of chronic ischaemic heart disease. The fall continued after this revision (with the rates being lower in 1980 than in 1979) and was seen when only deaths from acute myocardial infarction (International Classification of Diseases 410 in both revisions) were examined across the years presented in this report.

The fall in ischaemic heart disease in the United Kingdom was smaller and occurred later than the fall in the USA but was consistent in all regions and in men and women; although it occurred at all ages between 35 and 64, it was greatest in the youngest age group (35-44). Thus any attempt to explain this trend must take into consideration factors occurring across these demographic boundaries. Fat intake apparently started to decline about five years before the death rates started to fall, but the decline was similar in each age group. We could not distinguish between the fat intake of men and women, but the food survey ${ }^{6}$ reflects food going into households and food eating patterns in men and women in the same household may be similar. Fat intake fell in each region and there was a suggestion that the regions with the greatest fall in ischaemic heart disease had shown the largest reduction in fat intake. Although the change in death rates would fit in well with a change in fat intake, the regions with the highest prevalence of ischaemic heart disease did not have the highest dietary fat intake, and this is obviously not enough to explain the large regional differences in the death rates.

The changes in the smoking habits of adults over the past two decades differed between men and women: in men there was an initial decline in the proportion of smokers then a plateau followed by a larger decline after 1973-4, and in women there was an increase until 1973-4, after which there was only a small decline. It is difficult to relate these changes to the decline in deaths from ischaemic heart disease that occurred after 1973-4 especially as this was similar in men and women. If the change in type of smoking (reduced tar and nicotine contents and possibly also carbon monoxide with some kinds of filter tips) was responsible rather than the amount smoked it took a long time for the change to be reflected by a decline in deaths from ischaemic heart disease. Nevertheless, substantial changes in smoking habits both preceded and accompanied the decline in the death rate and it is possible that there was a relation.

Factors other than changes in lifestyle must be considered. In particular, changes in medical care may have occurred that reduced the case fatality of those who suffered a heart attack, so that at least part of the fall in deaths from ischaemic heart disease may have been due to improved survival of those already affected by the disease rather than a true reduction in incidence. The decline started well after the introduction of coronary care 
units and was too large and consistent to be explained by preventive surgery such as coronary artery bypass grafts. A critical examination of the time trends in the use of beta-blocking drugs for the treatment of angina or hypertension might be worth while. The disproportionate decline in the death rates in the youngest age groups in both men and women might be related to either better access to or a greater benefit from medical care. This might apply not only to the management of acute myocardial infarction but to treatment and counselling after infarction (that is, use of beta-blockers and advice on smoking). A change in the natural history of ischaemic heart disease such that it became a "milder" disease might provide an explanation, but why this happened so much later in the United Kingdom than in the USA and Australia would need to be established. A more detailed examination of the changes in lifestyle and medical practice was beyond the scope of this report.

A decline in the rate of death from ischaemic heart disease is thus now apparent; it has many consistencies with changes in fat intake but fewer with changes in smoking habits that have occurred in the UK. If this is the start of a continuing decline in the rate of death from this disease in this country a case may be made for detailed examination of changes in lifestyle and medical practice on a prospective basis to try to find the explanation.
We are grateful to the Tobacco Advisory Council for making available the data on smoking habits collected by Research Services Ltd.

\section{References}

1 Levy RI. Declining mortality in coronary heart disease. Arteriosclerosis $1981 ; 1: 312-25$.

2 Florey CduV, Melia RJW, Darby SC. Changing mortality from ischaemic heart disease in Great Britain 1968-76. Br Med f 1978;i:635-7.

${ }^{3}$ Office of Population Censuses and Surveys. Mortality statistics (cause) England and Wales, 1980. London: HMSO, 1982.

4 Office of Population Censuses and Surveys. Mortality statistics, England and Wales, 1968-79. London: HMSO, 1970-81.

${ }^{5}$ Registrar General for Scotland. Annual report, 1968-80. Edinburgh HMSO, 1969-81.

${ }^{6}$ Ministry of Agriculture, Fisheries and Food (National Food Survey Committee). Household food consumption and expenditure, 1968-79. London: HMSO, 1970-81.

${ }^{7}$ Lee PN, ed. Statistics of smoking in the United Kingdom. 7th ed. (Research paper No 1.) London: Tobacco Research Council, 1976.

* Office of Population Censuses and Surveys. General household survey, 1972 London: HMSO, 1975.

9 Office of Population Censuses and Surveys. General household survey, 1980 London: HMSO, 1982.

\title{
Neurological effects of recombinant human interferon
}

\author{
HOWARD SMEDLEY， MAUREEN KATRAK，KAROL SIKORA，TERENCE WHEELER
}

\begin{abstract}
Ten women with advanced locally recurrent breast cancer who had failed to respond to radiation and hormonal and cytotoxic agents were given up to 12 weeks of recombinant leucocyte interferon $20 \times 10^{6} \mathrm{U} / \mathrm{m}^{2}$ daily or $50 \times 10^{6} \mathrm{U} / \mathrm{m}^{2}$ three times a week. Within one hour of administration influenza-like symptoms began, which one week later were superseded by lethargy, anorexia, and nausea, with a consequent loss of weight in most patients. Other side effects included profound somnolence, confusion, paraesthesia, and (in one patient) signs of an upper motor neurone lesion in the legs. All these effects together with increased slow wave activity in electroencephalograms from all patients during treatment disappeared when interferon was withdrawn and did not recur on reintroducing the drug at a lower dosage.

Studies are continuing to determine the mechanisms of these effects.
\end{abstract}

\footnotetext{
Ludwig Institute for Cancer Research, Addenbrooke's Hospital, Cambridge

HOWARD SMEDLEY, MB, FRCR, senior clinical scientist and honorary senior registrar

MAUREEN KATRAK, SRN, clinical research sister

KAROL SIKORA, MRCP, FRCR, director and honorary consultant in radiotherapy and oncology
}

Department of Radiotherapy, Addenbrooke's Hospital, Cambridge TERENCE WHEELER, FRCR, consultant in radiotherapy and oncology

\section{Introduction}

We are conducting a clinical trial to study the efficacy and safety of highly purified human leucocyte $A$ interferon produced by recombinant DNA technology ${ }^{1}$ in patients with advanced breast cancer. We report here a previously undescribed complication of interferon-namely, dose dependent, reversible central nervous system toxicity.

\section{Patients and results}

All the patients studied had advanced locally recurrent breast cancer which had failed to respond to conventional radiation and hormonal and cytotoxic treatment. Recombinant leucocyte interferon (Hoffmann La Roche) was administered intramuscularly in a dose of either $20 \times 10^{6} \mathrm{U} / \mathrm{m}^{2}$ daily or $50 \times 10^{6} \mathrm{U} / \mathrm{m}^{2}$ three times a week, both regimens being continued for up to 12 weeks. At the time of this report 10 patients had been studied (table).

After initiation of interferon treatment a predictable pattern of side effects common to all patients occurred. Within one hour of injection fever of up to $40^{\circ} \mathrm{C}$ was noted, which could be subsequently successfully prevented with paracetamol $1 \mathrm{~g}$ four times a day. Paracetamol was also effective for headache and myalgia, which were also common during the first four days of treatmen:. No patients developed any immediate anaphylactic reactions, nor was there any change in blood pressure or other vital signs after injection of interferon. Tachyphylaxis against the influenza-like symptoms rapidly developed over the first week, but at one week these side effects were superseded by lethargy and anorexia. Anorexia was often accompanied by nausea but only occasionally by vomiting; it was enough to cause four patients to refuse food altogether for periods of up to one week, with a subsequent fall in weight of greater than $10 \%$ of original body weight. A transient fall in the total white cell and platelet counts was observed but in no patient was this severe enough to warrant withdrawal of treatment. Renal function remained unaltered. Liver function tests showed 